\title{
Valuation of the flexibility in decision-making for revamping installations -A case from fertilizer plants
}

\author{
WANG Zhen* and LI Liangjun \\ School of Business, China University of Petroleum, Beijing 102249, China \\ (C) China University of Petroleum (Beijing) and Springer-Verlag Berlin Heidelberg 2010
}

\begin{abstract}
This paper puts forward a valuation model for the flexibility of revamping urea plants based on the substitutability of switching between the internationally accepted fertilizer feedstock fuel oil and natural gas. The paper first builds a stochastic mean-reversion model for fuel oil prices and natural gas prices respectively, then estimates and tests the parameters using the fuel oil and natural gas prices data from the U.S. market. This paper also conducts a sensitivity analysis with important parameters. The results show that the real option method can be applied successfully to evaluate the flexibility in decisionmaking for revamping installations in fertilizer plants or other similar plants.
\end{abstract}

Key words: Real option, fertilizer installations, fuel oil, natural gas, mean reversion

\section{Introduction}

The irreplaceable role fertilizer plays in agriculture has insured fertilizer plants, especially those producing urea, great importance in the market. In the total costs of these fertilizer plants, the cost of energy accounts for about $70 \%$. In China, fertilizer plants mainly use coal, fuel oil and natural gas as feedstock, whereas fuel oil and natural gas are the general choices abroad because coal can cause heavy pollution. The prices of fuel oil and natural gas follow different tracks with different volatilities, which allow fertilizer plants to choose low-price feedstock when price difference occurs. To do so, the fertilizer plant has to revamp its original installations. The revamped installations could be switched to use fuel oil as feedstock to produce urea when natural gas price is higher than fuel oil price, and vice versa. As the urea plant revamping is an obviously flexible strategic decision, the traditional discounted cash flow (DCF) method tends to cause large deviations. Thus we can apply the real option method to evaluate the investment decision (Dixit and Pindyck, 1994; Gibson and Schwartz, 1990; Pennings and Lint, 1997; Trigeorgis, 1996).

\section{The real option model for the flexibility in feedstock choice for fertilizer plants}

The basic decision-making process using the real option method is as follows: 1) to identify the type of real option in the decision; 2) to build a real option model; 3) to choose

\footnotetext{
* Corresponding author. email: wangzhen@cup.edu.cn

Received November 23, 2009
}

a method to calculate the value of the option. This paper compares the costs in two situations-cost when producing urea with a single feedstock and cost when producing urea with feedstock switching between fuel oil and natural gas by the minimum cost principal-in order to value the flexibility in feedstock choice for long term synthetic ammonia-urea installations (Brennan and Schwartz, 1985; Ekern, 1988; McDonald and Siegel, 1986; Tourinho, 1979).

There are two kinds of feedstock to choose when producing synthetic ammonia-urea: fuel oil and natural gas (Ramón, 2008). According to the time series data, we assume that the flexibility in feedstock choice is based on the monthly updated data. Taking that the feedstock of the fertilizer plant is switched from fuel oil to natural gas as an example (oil to gas), in the forthcoming month n, the average prices for fuel oil and natural gas are denoted as $P_{\text {oil }}(n)$ and $P_{\text {gas }}(n)$ respectively. According to the quantities of fuel oil and natural gas required for heating and for feedstocks per tonne of urea, as well as the prices of fuel oil and natural gas, the total cost of fuel oil and natural gas per tonne of urea can be calculated, denoted as $C_{\text {oil }}(n)$ and $C_{\text {gas }}(n)$ respectively. Setting the fuel oil price as the base price of material prices, then in month $\mathrm{n}$, the value of the real option for feedstock in producing urea using oil-to-gas installations is as follows:

$$
V_{\mathrm{o}-\mathrm{g}}(n)=\max \left(\left(C_{\mathrm{oil}}(n)-C_{\mathrm{gas}}(n)\right), 0\right)
$$

Where, $V_{\mathrm{o}-\mathrm{g}}(n)$ is the value of oil-gas installations of the month $\mathrm{n}$ in the future.

In the equation (1), we assume that fuel oil is transported by sea, adopting CIF price (cost, insurance and freight price).

If the work life cycle of the revamped installations is $N$ 
months, then the present value of the real option per unit yield with oil-to-gas installations is:

$$
V_{\mathrm{o}-\mathrm{g}}=\sum_{n=1}^{N} V_{\mathrm{o}-\mathrm{g}}(n) /\left(1+r_{f}\right)^{(n-1) / 12}
$$

In the equation (2), $V_{\mathrm{o}-\mathrm{g}}$ is the total value of oil-gas installations. $V_{\mathrm{og}}(n)$ is the value of oil-gas installations of the month $n$ in the future. $r_{f}$ is the risk-free annual rate of return.

Similarly, the value of the real option for gas-to-oil installations is:

$$
V_{\mathrm{g}-\mathrm{o}}(n)=\max \left(\left(C_{\mathrm{gas}}(n)-C_{\mathrm{oil}}(n)\right), 0\right)
$$

If the work life cycle of the revamped installations is $N$ months, then the present value of that of gas-to-oil installations is:

$$
V_{\mathrm{g}-\mathrm{o}}=\sum_{n=1}^{N} V_{\mathrm{g}-\mathrm{o}}(n) /\left(1+r_{f}\right)^{(n-1) / 12}
$$

Where, $r_{f}$ is the risk-free annual rate of return.

\section{Model for the price of fuel oil and natural gas}

In whatever method we choose for evaluating an investment decision, future price is of great significance in the evaluation process. It is also important to describe the price model using the real option method. The price changes of commodities are usually described as a stochastic process. The price changes of underlying commodities such as fuel oil and natural gas, however, are generally described as a geometric Brownian motion. But in the long run, the prices of fuel oil and natural gas follow the law of value, which will be better covered by the mean reversion process. In the global energy consumption mix, crude oil which is globally traded and takes the major part, while natural gas is only regionally traded. The price of fuel oil, which is the main fuel in industrial fields, has a close relation with the price of crude oil. Although the price of natural gas, as the substituted fuel for fuel oil, tracks the price of crude oil, while the natural gas price does not have a direct influence on the fuel oil price. (Fig. 1)

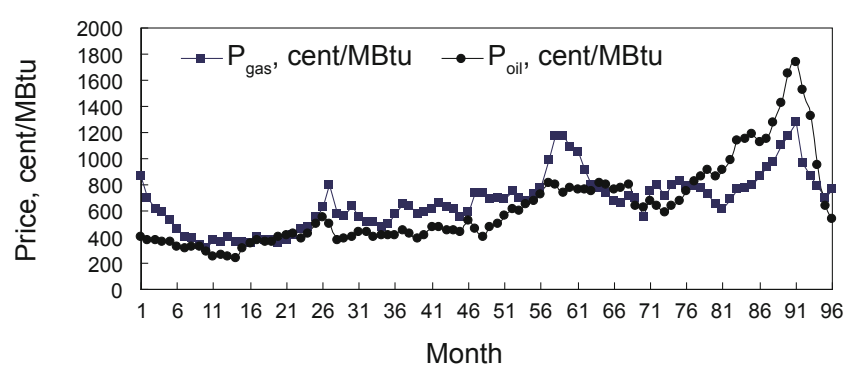

Fig. 1 Prices of fuel oil and natural gas

The Granger causality test based on the monthly price of fuel oil and natural gas in U.S. market from Jan. 2001 to Dec. 2008 shows that the price change of fuel oil is the leading cause of the price change of natural gas (Table 1).
As the prices of crude oil and fuel oil are highly correlated, it is proper to use the mean reversion process to build the fuel oil price model, and based on which, the price convergence process can be used to build the natural gas price model (McDonald and Siegel, 1986; Schwartz, 1997; Gibson and Schwartz,1990).

Table 1 Granger causality test

\begin{tabular}{cccc}
\hline Null hypothesis & Observations & F-statistic & Probability \\
\hline Oil does not Granger cause gas & 94 & 4.84836 & 0.01003 \\
Gas does not Granger cause oil & & 1.22066 & 0.29993 \\
\hline
\end{tabular}

\subsection{Model for fuel oil price}

As in the case discussed above, the model of mean reversion process of fuel oil price can be built as follows (Kellogg and Charnes, 2000; Lima, 2005; Schwartz and Moon, 2000):

$$
\frac{\mathrm{d} P_{\text {oil }}}{P_{\text {oil }}}=\alpha \cdot \log \left(\frac{\bar{P}_{\text {oil }}}{P_{\text {oil }}}\right) \cdot \mathrm{d} t+\sigma_{\text {oil }} \cdot \mathrm{d} z_{\text {oil }}
$$

The equation (5) is built based on continuous-time. Since the fuel oil and natural gas prices are monthly data, the model can be transformed into a discrete-time type:

$$
r_{\text {oil }}(n)=\log \left(\frac{P_{\text {oil }}(n+1)}{P_{\text {oil }}(n)}\right)=\alpha \cdot \log \left(\frac{\bar{P}_{\text {oil }}}{P_{\text {oil }}(n)}\right)+\sigma_{\text {oil }} \cdot \mathrm{d} z_{\text {oil }}
$$

Where, $\bar{P}_{\text {oil }}$ represents the long-term mean value of oil price reversion. $P_{\text {oil }}(n+1)$ is the fuel oil price in month $n+1$, $\alpha$ stands for the mean reversion rate, the value of which indicating the speed in which the fuel oil price reverts towards the mean value and $Z_{\mathrm{oil}}$ represents the random walk of the fuel oil price. $\sigma_{\text {oil }}$ is the volatility of oil price. $r_{\text {oil }}(n)$ is the logarithmic form of increase rate of oil price.

\subsection{Model for natural gas price}

Since the price fluctuation of natural gas tracks the price of fuel oil, the model for natural gas price can be:

$$
\frac{\mathrm{d} P_{\text {gas }}}{P_{\text {gas }}}=\beta \cdot \log \left(\frac{P_{\text {oil }}}{P_{\text {gas }}}\right) \cdot \mathrm{d} t+\sigma_{\text {gas }} \cdot \mathrm{d} z_{\text {gas }}
$$

In like manner, the respective increment-time model should be:

$$
r_{\text {gas }}(n)=\log \left(\frac{P_{\text {gas }}(n+1)}{P_{\text {gas }}(n)}\right)=\beta \cdot \log \left(\frac{P_{\text {oil }(n+1)}}{P_{\text {gas }}(n)}\right)+\sigma_{\text {gas }} \cdot \mathrm{d} z_{\text {gas }}
$$

where, $P_{\text {oil }}(n+1)$ is the natural gas price in month $n+1, \beta$ stands for the price convergence rate, the value of which indicates the speed at which the natural gas price converges towards the mean value and $Z_{\text {gas }}$ represents the random walk of the natural gas price. $\sigma_{\text {gas }}$ is the volatility of natural gas price. $r_{\text {gas }}(n)$ is the logarithmic form of the rate of increase of natural gas price.

\subsection{Parameters estimation and test in the models for fuel oil and natural gas prices}

Currently, the fuel oil price in China is fully market- 
oriented, while natural gas price is still under government regulation. However, reform of natural gas price toward market orientation is the future trend. Thus, China's urea production enterprises should set their strategy with the consideration of future development. For data consistency, we use the data of natural gas prices in North America, and the CIF price of fuel oil with $1 \%$ sulfur content for industrial use in New York Harbor, in the time range from Jan. 2001 to Dec. 2008.

\subsubsection{Parameter estimation}

This paper uses the maximum likelihood estimation method to estimate the parameters in the models for fuel oil price and natural gas price. Given the set of $P_{1}$ consisted of initial prices of $P_{\text {oil }}$ and $P_{\text {gas. }}$. Also given the realization process $P$ which stands for the random process of $P_{\text {oil }}$ and $P_{\text {gas }}$. When the natural logarithm of occurrence probability of $P$ is maximized,

$\Psi=\left\{\bar{P}_{\text {oil }}, \sigma_{\text {gas }}, \sigma_{\text {oil }}, \alpha, \beta\right\}$ is a series of optimum parameters $\psi^{*} \cdot \psi^{*}$ is defined as :

$$
\psi^{*}=\arg \max \left[\log \left(\operatorname{prob}\left(P \mid \varphi, P_{1}\right)\right)\right]
$$

$Z_{\text {oil }}$ and $Z_{\text {gas }}$ follow the independent and identical standard normal random process. At a given stage $n(n=1,2, \cdots, N)$, the historical process can be defined as:

$$
\begin{aligned}
h(n)= & \left\{Z_{\text {oil }}(1), Z_{\text {gas }}(1), Z_{\text {oil }}(2), Z_{\text {gas }}(2), \cdots, Z_{\text {oil }}(N-1),\right. \\
& \left.Z_{\text {gas }}(N-1)\right\}
\end{aligned}
$$

The log-likelihood maximization can be concluded from a sample of $N$ data points:

$$
\begin{aligned}
M l l= & \max _{\psi} \sum_{n=1}^{N-1}\left[\log \left(\operatorname{prob}\left(Z_{\text {oil }}(n) \mid \varphi, h(n)\right)\right)\right. \\
& \left.+\log \left(\operatorname{prob}\left(Z_{\text {gas }}(n) \mid \varphi, h(n)\right)\right)\right]
\end{aligned}
$$

Considering the equations (6) and (8), the random shock can be expressed as:

$$
\begin{aligned}
& Z_{\text {oil }}(n)=\frac{1}{\sigma_{\text {oil }}} \cdot \log \left(\frac{P_{\text {oil }}(n+1)}{P_{\text {oil }}(n)}\right)-\frac{\alpha}{\sigma_{\text {oil }}} \cdot \log \left(\frac{\bar{P}_{\text {oil }}}{P_{\text {oil }}(n)}\right) \\
& Z_{\text {gas }}(n)=\frac{1}{\sigma_{\text {gas }}} \cdot \log \left(\frac{P_{\text {gas }}(n+1)}{P_{\text {gas }}(n)}\right)-\frac{\beta}{\sigma_{\text {gas }}} \cdot \log \left(\frac{P_{\text {oil }}(n+1)}{P_{\text {gas }}(n)}\right)
\end{aligned}
$$

So $M l l$ can be expressed as:

$$
\begin{aligned}
M l l= & \max _{\psi}(N-1) \cdot \log \left(\frac{1}{2 \pi \cdot \sigma_{\text {oil }} \cdot \sigma_{\text {gas }}}\right) \\
& -\frac{1}{2} \cdot \sum_{n=1}^{N-1}\left[Z_{\text {oil }}(n)^{2}+Z_{\text {gas }}(n)^{2}\right]
\end{aligned}
$$

Substituting equations (12) and (13) into the likelihood equations (14), the estimated parameter is then obtained when Mll takes the maximum value. Resorting to MATLAB to optimize Mll, we can get the parameter of that model, which is the maximum likelihood solution to the likelihood function.
The estimated parameters' values are shown in Table 2 .

Table 2 Estimated parameter value

\begin{tabular}{cccccc}
\hline$P_{\text {oil }}^{-}$ & $\alpha^{*}$ & $\beta^{*}$ & $\sigma_{\text {oil }}{ }^{*}$ & $\sigma_{\text {gas }}{ }^{*}$ & $M l{ }^{*}$ \\
\hline 623.3941 & 0.0292 & 0.1244 & 0.1050 & 0.1063 & 157.4081 \\
\hline
\end{tabular}

Notes: $\alpha^{*}, \beta^{*}, \sigma_{\text {oil }}{ }^{*}, \sigma_{\text {gas }}{ }^{*}$, and $M l l^{*}$ is the estimated value of the parameters $\alpha, \beta, \sigma_{\text {oil }}, \sigma_{\text {gas }}$, and Mll.

\subsubsection{Parameters test}

Substitute the estimated parameter into equations (12) and (13), to obtain the values of $Z_{\text {oil }}(n)$ and $Z_{\text {gas }}(n)$. Use MATLAB to conduct the K-S standard normal distribution test. The results are shown in Table 3 and Table 4.

Table $3 Z_{\text {oil }}(n)$ standard normal distribution test result

\begin{tabular}{cccc}
\hline Null hypothesis & $P$ & K-S statistic value of $Z_{\text {oil }}(n)$ & Critical value \\
\hline 0 & 0.4483 & 0.0872 & 0.1375 \\
\hline
\end{tabular}

Table $\mathbf{4} Z_{\mathrm{gas}}(n)$ Standard normal distribution test result

\begin{tabular}{cccc}
\hline Null hypothesis & $P$ & K-S statistic value of $Z_{\text {gas }}(n)$ & Critical value \\
\hline 0 & 0.3075 & 0.0979 & 0.1375 \\
\hline
\end{tabular}

As the K-S statistic values of $Z_{\text {oil }}(n)$ and $Z_{\text {gas }}(n)$ are both smaller than the critical value, the null hypothesis is accepted, which means $Z_{\text {oil }}(n)$ obeys standard normal distribution and the results are significant.

\section{Model application}

\subsection{Case background}

The cost of feedstock used in this real option model is jointly determined by the price of fuel oil and natural gas and by an energy-cost parameter. Enterprises differ in capacity scales and technique processes, which lead to varied energycost parameters, resulting in various costs. In this paper, we choose a practical case, which comes from our private database. In the case, we will calculate the specific energycost parameter of Company A with the real option model. The company has an installation with a yearly production capacity of 300,000 tonnes of synthetic ammonia and 520,000 tonnes of urea, and a cost of $470.57 \mathrm{~kg}$ fuel oil as feedstock for per tonne urea before revamping installations and $514.01 \mathrm{~m}^{3}$ natural gas for per tonne urea after revamping installations.

Commissioning in 1998, the synthetic ammonia installation adopts the gas producing process from Texaco Corporation, the urea installation adopts the $\mathrm{CO}_{2}$ stripping process from Stamicarbon Corporation of Netherlands. The installation used fuel oil as the feedstock before, and was revamped to switch between fuel oil and natural gas in 2003 . Both the technology of partial oxidation of fuel oil and that of the revamped partial oxidation of natural gas are from Texaco Corporation. This installation holds two sites of synthesis gas production systems (feedstock switching system), which can be switched while the installation is power off. 
Through unit conversion, the heating cost from fuel oil for per tonne of urea is $19.027 \mathrm{MBtu} /$ tonne. Together with the price of fuel oil as feedstock, $P_{\text {oil }}($ cent $/ \mathrm{MBtu})$, the total fuel oil cost for per tonne of urea can be calculated as $C_{\text {oil }}$ (dollar/ tonne $)=19.027 \cdot P_{\text {oil }} \times 10^{-2}$.

\subsection{Price simulation and option value calculation for fuel oil and natural gas}

This paper tries to simulate the monthly price of fuel oil and natural gas using the Monte Carlo simulation method. Then the price data can be converted to get monthly feedstock cost for per tonne of urea based on the energy consumption parameters of the plant. Furthermore, the option value can be calculated according to the above real option value model.

Before revamping installations, the urea production plant uses fuel oil as its single feedstock. After revamping installations, a set of synthesis gas plants is added and the feedstock could be switched to the lower cost one while the power is off. By this way it could reduce cost in the urea producing process. Hence, we could first calculate the real option value of the feedstock selection in the investment feasibility study. Then, we can compare the real option value and the expense budget of revamping installations, executing the option only if the real option value is larger than the expense budget.

The monthly price data of fuel oil and natural gas in U.S. market from Jan. 2001 to Dec. 2008 come from EIA (Energy Information Agency of Department of Energy, the USA) website. After parameter estimation, firstly, we substitute the fuel oil price of Dec. 2008, $P_{\text {oil }}(0)=534.10 \mathrm{cent} / \mathrm{MBtu}$, and the natural gas price of Dec. $2008, P_{\text {gas }}(0)=762.65$ cent $/$ MBtu, in equation (6) and equation (8), to simulate the fuel oil and natural gas price in 180 months (from January 2009 to December 2023) using MATLAB. Considering this set of fertilizer production process was prevailing at the end of 1990s, while the work-life span of normal urea producing plant is 25 years, it is reasonable to simulate the next 15 years after 2009.

This petrochemical company has the plant with production capacity of 300,000 tonnes of synthetic ammonia and 520,000 tonnes of urea. Before revamping installations, the fuel oil consumption per tonne of urea is $470.57 \mathrm{~kg}$ (the device parameter given above); After revamping installations, the natural gas consumption per tonne of urea is $51401 \mathrm{~m}^{3}$ (the device parameter given above). With the above parameters we can convert the fuel oil and natural gas price in 180 months into the cost of fuel oil consumption, $C_{\text {oil }}(n)$, for urea production, and the cost of natural gas consumption, $C_{\text {gas }}(n)$, for urea production.

The real option value $V_{\mathrm{og}}(n)$ of per tonne urea production in the month $\mathrm{n}$ after revamping installations can be calculated according to equations (1), then based on equations (2) to discount the option value of these 180 months to the first month-January 2009, that is the real option value $V_{\text {o-g }}$ per production unit of this device after revamping installations.

According to the historical data of risk-free rate of return and the present economic situation, it is comparatively reasonable here to take $5 \%$ as the risk-free rate of return $\left(r_{\mathrm{f}}\right)$ in the next 15 years.
With MATLAB, we use the Monte-Carlo method to simulate 1000, 5000, 10000, 20000, 40000, 60000, 80000, 100000 paths, ten times separately, and to make the scatter trend as shown in Fig. 2, then based on the maximum difference of each 10 simulations to make the trend shown in Fig. 3.

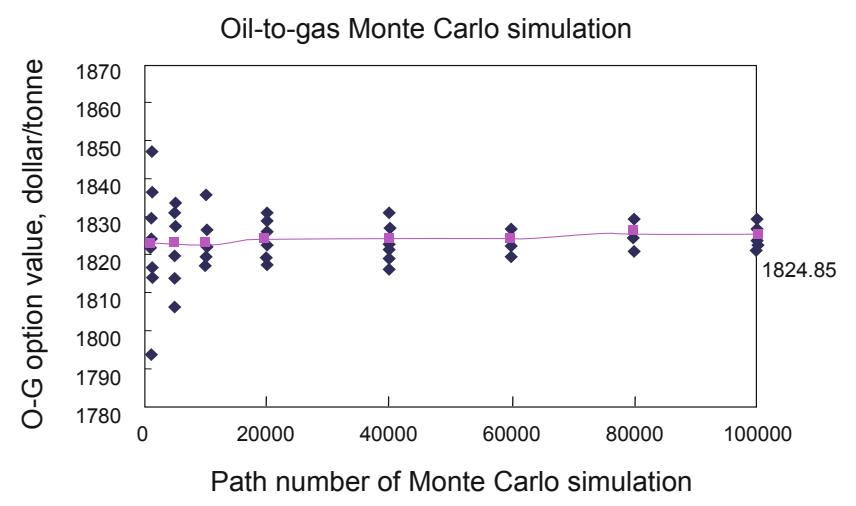

Fig. 2 Unit production mean value of oil-to-gas option in different paths

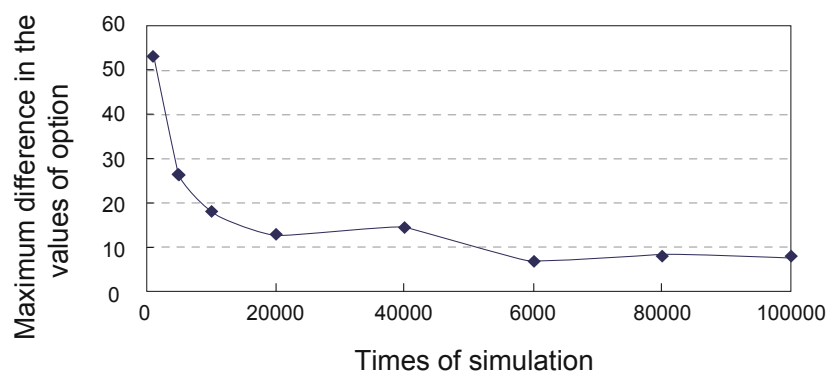

Fig. 3 Maximum difference of oil-to-gas unit production option value in multiple paths

Fig. 2 and Fig. 3 indicate that the more paths we simulate, the more convergent the results will be. We take the mean value of ten results of 10000 paths' simulation-1824.85\$ per tonne production of urea, as the feedstock selection option value, for this device after revamping oil-to-gas installations, i.e. $\bar{V}_{\text {o-g }}=1824.85$ dollar/tonne (urea), $\bar{V}_{\text {o-g }}$ is the cost value saved per tonne production of urea.

The calculation results of the real option value after revamping installations are as follows:

This plant was designed with the annual production of 520,000 tonnes of urea-43 thousand tonnes per month. For the situation when feedstock is switched from fuel oil to natural gas, the total real option value after revamping installations in the next 15 years should be $V_{\mathrm{o}-\mathrm{g}}=43 \cdot \bar{V}_{\mathrm{o}-\mathrm{g}}$ $=79.07$ million dollars.

For the situation when feedstock is switched from natural gas to fuel oil, the real option value per tonne urea will be $\bar{V}_{\text {o-g }}=1777.42$ dollar/tonne (urea) and total value of the real option $V_{\mathrm{g}-\mathrm{o}}=77.02$ million dollars. This real option value can be compared with expense budget, which is an important basis for the investment decision to revamp installations.

\subsection{Sensitivity analysis}

Influenced by uncertain factors like economic environment, historical events, etc, the parameters in the real option model have many uncertainties, which will cause deviation in the calculation of the option value. The deviation 
will furthermore influence the investment decision-making process of feedstock selection. Therefore this paper provides separate sensitivity analysis to risk-free return $r_{f}$, price volatility $\sigma$, price convergence coefficient $\beta$, mean reversion coefficient $\alpha$, mean value $\bar{P}_{\text {oil }}$ and project cycle.

\subsubsection{Effect of annual risk-free rate of return on real option value}

Because the annual rate of return of 15 years U.S. treasury bond fluctuates greatly, in this paper we take the approximate value $5 \%$ as the risk-free rate of return. In order to examine the influence of risk-free rate of return $\left(r_{f}\right)$ on the real option value, we evaluate the option in different risk-free rates of return. Take $r_{f}$ as $0,1 \%, 2 \%, \cdots, 10 \%$, using Monte Carlo to simulate the real option value per tonne urea production with 100,000 paths, Then we take the mean value of them as shown in Fig. 4 and Fig. 5.

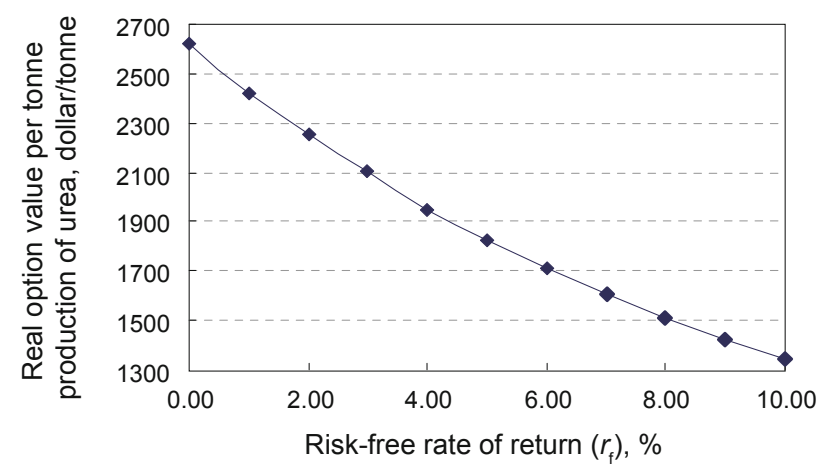

Fig. 4 Influence of risk-free rate of return on the real option value for the oil-to-gas option

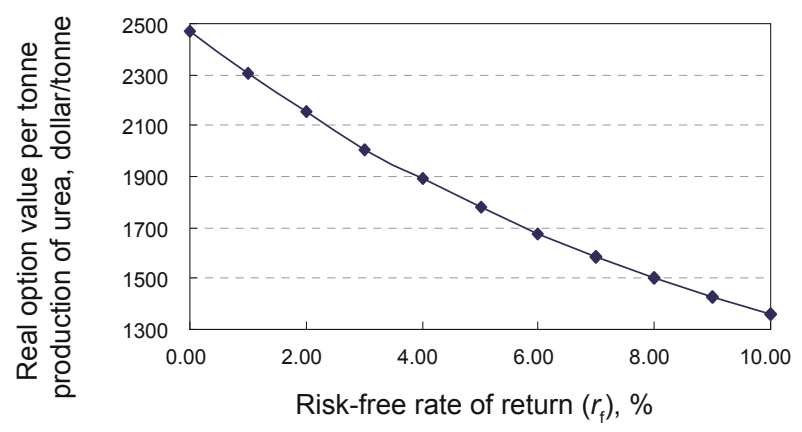

Fig. 5 Influences of risk-free rate of return on the real option value for the gas-to-oil option

Fig. 4 and Fig. 5 show that with increasing risk-free rate of return $\left(r_{\mathrm{f}}\right)$, the real option value for the oil-to-gas and gas-to-oil options steadily decreases. That is because with increasing risk-free rate, the discount rate of each period's option value also increases, causing the real option value of each selection option decreases steadily.

\subsubsection{Effect of price volatility of natural gas on real option value}

To examine the effect of price fluctuating rate on the real option value, $\sigma_{\text {oil }}$ is taken as $0, \sigma_{\text {oil }}^{*}, 2 \sigma_{\text {oil }}^{*}$, and $\sigma_{\text {gas }}$ is taken as $0,0.04,0.08,0.12,0.16,0.2,0.24$, and Monte Carlo is used to simulate the real option value per tonne urea production for oil-to-gas and gas-to-oil options with 100,000 paths. Then take the mean value of them (Fig. 6 and Fig. 7).

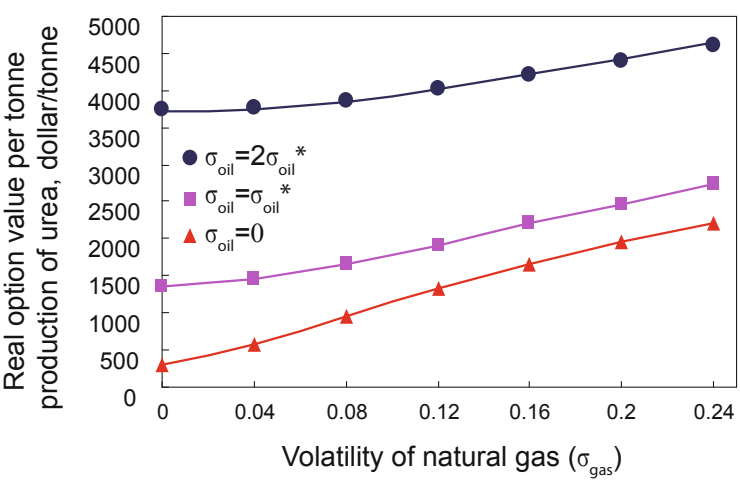

Fig. 6 Influence of fluctuating rate of natural gas price on the real option value for the oil-to-gas option

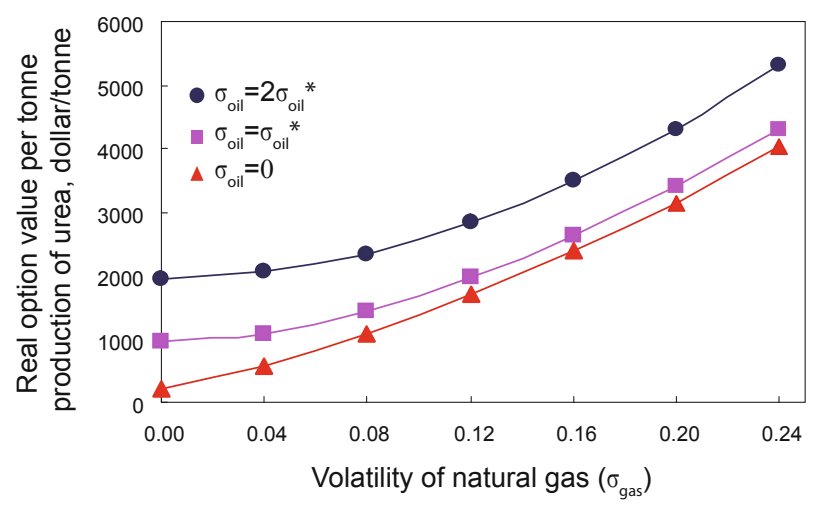

Fig. 7 Influence of fluctuating rate of natural gas price on the real option value for the gas-to-oil option

From Fig. 6 and Fig. 7, the real option value of both oil-to-gas and gas-to-oil has a positive correlation with the fluctuating rate of natural gas price. However, $\sigma_{\text {gas }}$ has a larger influence on real option value than $\sigma_{\text {oil }}^{*}$. The model shows that fuel oil price is the basic price, and the natural gas price is convergent towards it. The fluctuating rate of natural gas price determines the real option value to a great extent .

4.3.3 Effect of price convergence rate on the real option value

To examine the effect of price convergence rate $(\beta)$ on the real option value for oil-to-gas and gas-to-oil options, $\beta$ is taken as $0,0.5,1.0,1.5, \ldots, 2.5$, and Monte Carlo simulation is conducted to simulate the real option value per tonne urea production for oil-to-gas and gas-to-oil options with 100,000 paths. Then take the mean value of them (Fig. 8 and Fig. 9).
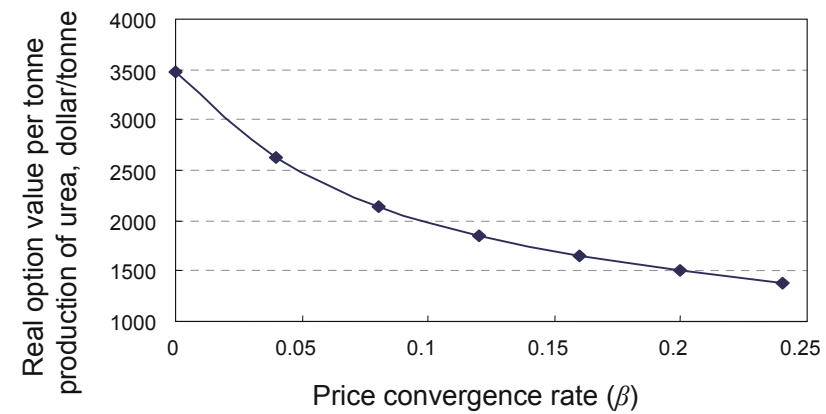

Fig. 8 Influences of gas price convergence rate $(\beta)$ on the real option value for the oil-to-gas option 


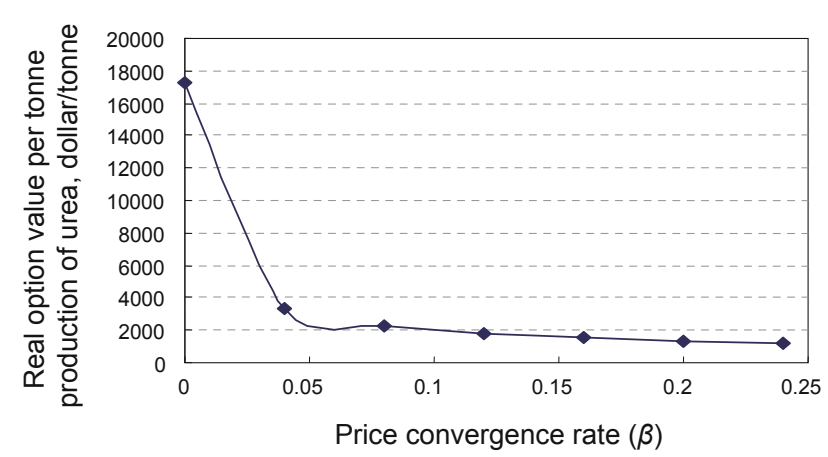

Fig. 9 Influences of gas price convergence rate $(\beta)$ on the real option value for the gas-to-oil option

From Fig. 8 and Fig. 9, the real option value of both oil-to-gas and gas-to-oil options has a negative correlation with the value convergence rate $\beta$. That is because the more convergence the two prices, the smaller the value difference of the two real option values.

\subsubsection{Effect of mean-reversion rate and mean value on real option value}

To examine the effect of mean-reversion rates $(\alpha)$ and mean value $\bar{P}_{\text {oil }}$ on the real option value, is taken $0, \bar{P}_{\text {oil }}^{*}$, $2 \bar{P}_{\text {oil }}^{*}$, and $\alpha$ is taken as $0,0.01,0.02,0.03,0.04,0.05,0.06$, in MATLAB program and the Monte Carlo simulation is conducted to simulate the real option value per tonne urea production for oil-to-gas and gas-to-oil options with 100,000 paths. Then take the mean value of them (Fig. 10 and Fig. 11).

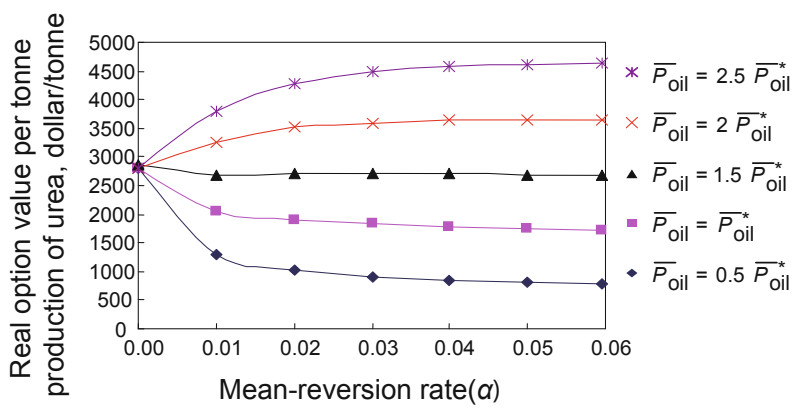

Fig. 10 Influences of mean-reversion rate and mean value on the real option value for oil-to-gas option

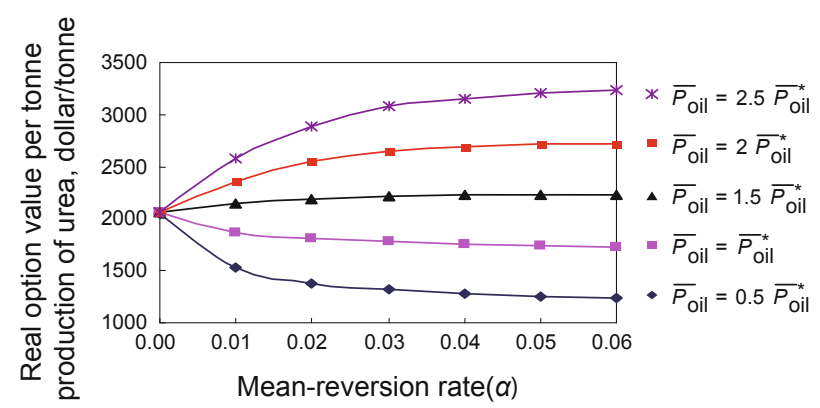

Fig. 11 Influences of mean-reversion rate and mean value on the real option value for gas-to-oil option
From Fig. 10 and Fig. 11, the real option value of both oilto-gas and gas-to-oil options has a positive correlation with mean value $\bar{P}_{\text {oil }}$. When $\bar{P}_{\text {oil }}$ takes a small value, the real option value has a negative correlation with mean-reversion rate $(\alpha)$; when $\bar{P}_{\text {oil }}$ takes a large value, real option value has a positive correlation with mean-reversion rate $(\alpha)$.

\subsubsection{Effect of project cycle on option value}

This part examines the impact of different project cycles on the option value. Take project cycle as 3, 6, 9,, 24 years accordingly, using Monte Carlo simulation to simulate the unit production value of the option with 100,000 paths. Then take the mean value of them (Fig. 12).

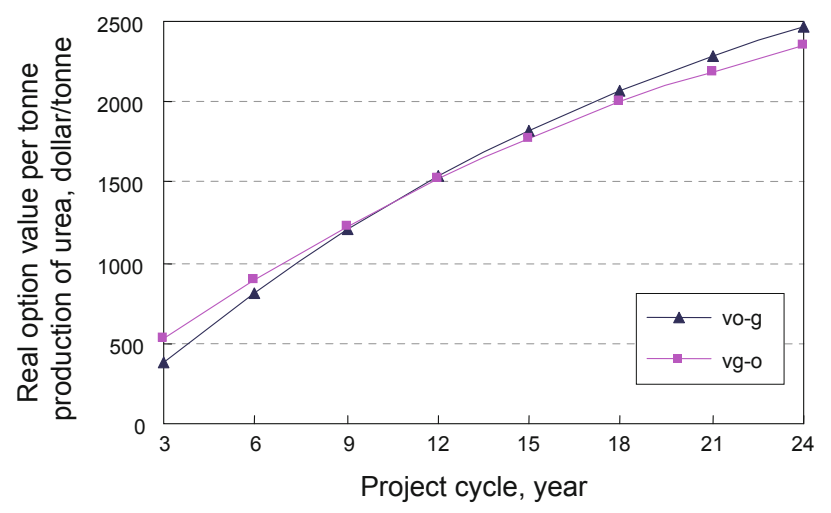

Fig. 12 Influences of project cycle on the real option value for oil-to-gas and gas-to-oil options

From Fig. 12, value of both oil-to-gas and gas-to-oil real option has a positive correlation with project cycle. When project cycle is short, real option value of oil-to-gas is smaller than that of gas-to-oil. When project cycle exceeds 11 years, real option value of oil-to-gas is larger.

\section{Conclusions}

Applying real option method, this paper evaluates, the investment strategy of fuel-switching for fertilizer producing plants. This method exceeds traditional evaluation methods in evaluating installations with flexibility and production elasticity. Although this paper sets urea producing plants as an example to study the flexibility problem in chemical plants, the main idea and method can also apply to other fields as long as flexibility problem lies in producing and strategic decision-making processes. However, specific factors have to be considered in a certain enterprise. These include transportation fee of the feedstock, environment protection cost and other costs occurred when the feedstock is switched. In China, price regulation of natural gas and the trend of reform toward market orientation shall also be taken into consideration for future study.

\section{References}

Brennan M J and Schwartz E S. Evaluating natural resource investment. Journal of Business. 1985. 58 (2): 135-157

Dixit A and Pindyck R. Investment Under Uncertainty. Princeton, NJ: Princeton University Press. 1994

Ekern S. An option pricing approach to evaluating petroleum projects. 
Energy Economics. 1988. 91-99 (April)

Gibson R and Schwartz E. Stochastic convenience yield and the pricing of oil contingent claims. Journal of Finance. 1990. 45 (3): 959-976

Kellogg D and Charnes J. M. Real-options valuation for a biotechnology company. Financial Analysts Journal. 2000. May/June. 76-84

Lima G A C and Suslick S B. An integration of real options and utility theory for evaluation and strategic decision-making in oil development and production projects. SPE 94665 presented at the 2005 SPE Hydrocarbon Economics and Evaluation Symposium held in Dallas, TX, U.S.A. 3-5 April

McDonald R and Siegel D. 1986. The value of waiting to invest. Quarterly Journal of Economics. 101(4): 707-727

Pennings H P G and Lint L j O. The option value of advanced R\&D. European Journal of Operational Research. 1997. 103(1): 83-94
Ramón Y R. Real option valuation of free destination in long-term liquefied natural gas supplies. Energy Economics. 2008. 30(4): 1909-1932

Schwartz E S and Moon M. Rational pricing of internet companies. Financial Analysis Journal. 2000. 56(3): 62-275

Schwartz, E S. The stochastic behavior of commodity prices: implications for valuation and hedging. Journal of Finance. 1997. 52 (3). 923-973 (July)

Tourinho O A F. The Valuation of Reserves of Natural Resources: An Option Pricing Approach. University of California, Berkeley. PhD Dissertation. 1979

Trigeorgis L. Real Options: Managerial Flexibility and Strategy in Resource Allocation. Cambridge, Massachusetts: MIT Press. 1996.

(Edited by Zhu Xiuqin) 